\title{
Barrier's deficiency impact in food allergy course in children
}

\author{
Olga Pakholchuk \\ From EAACI Skin Allergy Meeting 2014 \\ Krakow, Poland. 18-20 September 2014
}

\section{Background}

It is believed that in many cases Food allergy (FA) develops due to the contact of the immune system with different allergens through affected skin and mucous barriers. Studies of the filaggrin mutations in atopic dermatitis showed informativity of the transepidermal water lost measurement (TEWL) in assessment of the skin barrier condition. Faecal calprotectin is marker of the inflammation that can be helpful in understand of the GIT mucous condition.

\section{Aim}

To investigate a possible relationship between the TEWL and stool calprotectin level as markers of the barrier's deficiency with severity of the FA and treatment response.

\section{Methods}

80 patients with skin symptoms of food allergy of different severity were under study. TEWL level, faecal calprotectin level were measured to identify the presence of the skin and mucous barrier's deficiency in children and it's change under treatment.

\section{Results}

High TEWL was associated with a more severe disease course and a poor response to treatment with antihistamines than in patients with less TEWL $(\mathrm{r}=, 5, \mathrm{P}<.05)$. Faecal calprotectin was elevated in $35 / 80$ patients $(43.7 \%)$ and was found to be significantly higher in patients with more severe FA symptoms $(\mathrm{P}<.05)$. Not all patients with positive stool marker $(45.7 \% 16 / 35)$ noticed unsteady stool in anamnesis. In addition, the most effective influence on the severity of the TEWL had topical treatment with

\footnotetext{
Zaporizhia State Medical University, faculty pediatria department, Zaporizhia,
} Ukraine

(c) 2015 Pakholchuk; licensee BioMed Central Ltd. This is an Open Access article distributed under the terms of the Creative Commons 